\title{
Erratum to: Emotional regulation difficulties and premenstrual symptoms among Israeli students
}

\author{
Inbal Reuveni ${ }^{1}$ - Rotem Dan ${ }^{2,3}$ - Ronen Segman ${ }^{1} \cdot$ Ron Evron $^{1} \cdot$ Sofia Laufer $^{1}$ • \\ Gadi Goelman $^{2}$ - Omer Bonne ${ }^{1} \cdot$ Laura Canetti $^{1,4}$
}

Published online: 2 September 2016

(C) Springer-Verlag Wien 2016

\section{Erratum to: Arch Womens Ment Health}

\section{DOI 10.1007/s00737-016-0656-y}

The original version of this article unfortunately inverted the authornames and are now corrected in this article. Also, the affiliations have been corrected.

The online version of the original article can be found at http://dx.doi. org/10.1007/s00737-016-0656-y

Inbal Reuveni

reuveni@hadassah.org.il

Rotem Dan

rotemyo@gmail.com

Ronen Segman

ronense@ekmd.huji.ac.il

Ron Evron

ron.evron@mail.huji.ac.il

Sofia Laufer

tsofiyal@hadassah.org.il

Gadi Goelman

gadig@hadassah.org.il
Omer Bonne

bonne@hadassah.org.il

Laura Canetti

lcanetti@hotmail.com

Department of Psychiatry, Hadassah Hebrew University Medical Center, Jerusalem, Israel

2 MRI/MRS Lab, The Human Biology Research Center, Department of Medical Biophysics, Hadassah Hebrew University Medical Center, Jerusalem, Israel

3 Edmond and Lily Safra Center for Brain Sciences (ELSC), The Hebrew University of Jerusalem, Jerusalem, Israel

4 Department of Psychology, The Hebrew University of Jerusalem, Jerusalem, Israel 